\title{
OCCURRENCE OF SPINA BIFIDA IN THE MAKERERE UNIVERSITY GALLOWAY COLLECTION: AN OSTEOLOGICAL ANATOMICAL STUDY
}

\author{
Buwembo William ${ }^{1}$, Obore Apolot Priscilla ${ }^{1}$, Ziraba Samuel $^{1}$, Kange Mesarch ${ }^{1}$, Munabi Ian Guyton ${ }^{1}$, Okori \\ Hilder $^{1}$, Namusoke Fatuma ${ }^{2}$, Mwaka Erisa ${ }^{1,8}$, and Luboga Samuel A. ${ }^{1}$ \\ ${ }^{1}$ Department of Anatomy, School of Biomedical Sciences, Makerere University College of Health \\ Sciences
}

${ }^{2}$ Department of Obstetrics and Gynaecology, School of Medicine, Makerere University College of Health Sciences

Correspondence to \&Erisa Mwaka: Department of Anatomy, School of Biomedical Sciences, Makerere University College of health Sciences. P.O.Box \& 7072, Kampala Uganda, Telephone: +256752575050 Email: erisamwaka@gmail.com

\begin{abstract}
Spina bifida is one of the commonest neural tube defects. Though food fortification with folic acid has been reported to reduce spina bifida, the incidence of spina bifida and the benefits of taking folic acid have not been documented in many developing countries including Uganda. This study set out to determine the incidence of spina bifida and related skeletal neural tube defects in the skeletons currently housed in the Galloway skeletal collection at Makererere University College of Health Sciences, Anatomy department with the aim of using the data to extrapolate on the usefulness of food fortification with folic acid. This was a descriptive cross sectional study on 226 skeletons in the Galloway osteological collection examined by an experienced anatomist for features of neural tube defects that ranged from non-fusion of the spinal arches to total absence of vertebral structures. Of the skeletons examined $43 / 226(19 \%)$ had spina bifida. Of these $38 / 43(88 \%)$ were male, suggesting a higher incidence of spina bifida in males than in the females. Overall $55.2 \%$ of the skeletons were within the age range of 20-55 years. This historical study highlights possible differences in the maternal micro nutrient status in the early months of pregnancy for various African populations as shown by the differences in the prevalence rates of minor spina bifida defects in the Galloway osteological collection. There is need for baseline studies on folic acid levels during pregnancy and the various local dietary sources of folic acid for Africans.
\end{abstract}

\section{Key words: Neural tube defects, osteology}

\section{BACKGROUND}

Spina bifida is one of the many neural tube defects or congenital anomalies of the central nervous system (Greene \& Copp, 2014). These defects are the result of failure of closure of the neural tube, which later develops into the brain and the spinal cord of the embryo during the third to fourth weeks of pregnancy. The extreme forms of spina bifida may manifest, as varying degrees of motor impairment, and in some cases is fatal (Padmanabhan, 2006). A population based study in USA observed that individuals with milder forms of spina bifida were ten-times more likely to die than normal healthy persons (Kancherla, Druschel, \& Oakley, 2014). In developing countries that lack the appropriate social support systems, these milder forms of spina bifida can be an additional source of stigma.

Globally, neural tube defects are among the top five most serious birth defects affecting approximately 300,000 births annually (Flores, Vellozzi, Valencia, \& Sniezek, 2014). The actual number of these defects in East Africa is unknown with estimates at 13 cases per 10,000 live births to 20 neural tube defect 
cases per 10,000 live births in a hospital based study in Kenya to between 3.3 to 6.9 per 10,000 live births in various parts of Kenya according to a recent population based study (Githuku et al., 2014). Current estimates show that 1400 children are born with spina bifida in Uganda annually (Warf, Wright III, \& Kulkarni, 2011). These estimates have also varied with time as demonstrated by records from Uganda's national referral hospital between 1953 and September 1955 which showed an incidence of 3.6 per 10,000 births (Simpkiss \& Lowe, 1961). An observational study found 67 neural tube defects per 10,000 births (Ochieng, Kiryowa, Munabi, \& Ibingira, 2011). It is now generally accepted that all women of child bearing age and pregnant women should consume 400 micrograms of folic acid daily to reduce the risk of having a pregnancy affected by neural tube defects particularly spina bifida (Botto, Moore, Khoury, \& Erickson, 1999). This study set out to determine the incidence of spina bifida and related skeletal neural tube defects in the skeletons currently housed in the Galloway skeletal collection at Makererere University College of Health Sciences, Anatomy department.

\section{METHODS AND METHODS}

This was a descriptive cross sectional study on the Galloway skeletal collection. This skeletal collection was built up by Professor Alexander Galloway, the first Head of department of Anatomy and the first dean of the medical school, Makerere University 19471962 (Wood, 2013). The skeletons were obtained from Mulago hospital morgue when individuals died and no immediate relatives claimed the bodies for burial. As much of the soft tissues as possible would then be cut off the bones manually using sharp knives and surgical blades, after which the major joints would be disarticulated and the skeletal remnants placed in a decomposition tank. These tanks had water and bacteria that would decompose all the soft tissue and leave behind clean bones that would be dried, degreased and labelled for long-term storage in the Galloway anthropological collection. At the time of the study the collection had 581 human skeletons from the Galloway collection of which $477(82 \%)$ were males and 104 $(18 \%)$ were female. Table 1 provides a summary of the nationalities of the different individuals who contributed their skeletons to the Galloway bone collection. The majority of the skeletons belonged to Rwandese and Burundi immigrants who at the time worked, as labourers on Sugar cane estates and others were refugees who had fled their countries because of violent ethnic uprisings.

A target sample size of 185 skeletons was obtained using a hypothesised prevalence of $50 \%$, confidence limits (delta) of $5 \%$ and a cluster effect of 1 for alpha=0.95, power of 0.90 from a total population of 581 skeletons using the L. Kish survey sampling formula (Kish, 1965). This was inflated by $22 \%$ allowance for error and or missing bones in the collection to give a final sample size of 226 skeletons. These were randomly selected with the aid of a set of random numbers and the Skeleton identification number. Each of the selected skeletons was examined by an experienced anatomist for features

\begin{tabular}{|c|c|c|}
\hline COUNTRY & $\begin{array}{l}\text { NUMBER OF } \\
\text { SKELETONS }\end{array}$ & $\begin{array}{l}\text { PERCENTAGE } \\
\text { COMPOSITIONS }\end{array}$ \\
\hline Rwanda & 203 & 35 \\
\hline Uganda & 193 & 33 \\
\hline Unknown & 67 & 12 \\
\hline Burundi & 60 & 10 \\
\hline Tanzania & 34 & 6 \\
\hline Congo & 12 & 2 \\
\hline Kenya & 12 & 2 \\
\hline Total & 581 & 100 \\
\hline
\end{tabular}


of neural tube defects that ranged from nonfusion of the spinal arches to total absence of vertebral structures.

Descriptive statistics were generated to summarize the number of skeletons identified with defects. This number was used to estimate the number of neural tube defects in the cohort represented by the bones in the collection. The numbers were then standardised to obtain the crude prevalence rates of spina bifida to allow for comparisons across the different tribes in the collection (Naing, 2000). Permission to use the bones in the collection for research was obtained from the department of Anatomy. No identifier details were used in analysis.

\section{RESULTS}

Forty three (43) of the 226 skeletons (19\%) were examined and found to have spina bifida. Of these $38 / 43(88 \%)$ were male, suggesting a higher incidence of spina bifida in males than in the females. Figure 1 shows examples of vertebrae from the different segments of the spine the arches did not fuse. Overall $55.2 \%$ of the skeletons were from individuals who at the time of death were within the age range of 20-55 years.
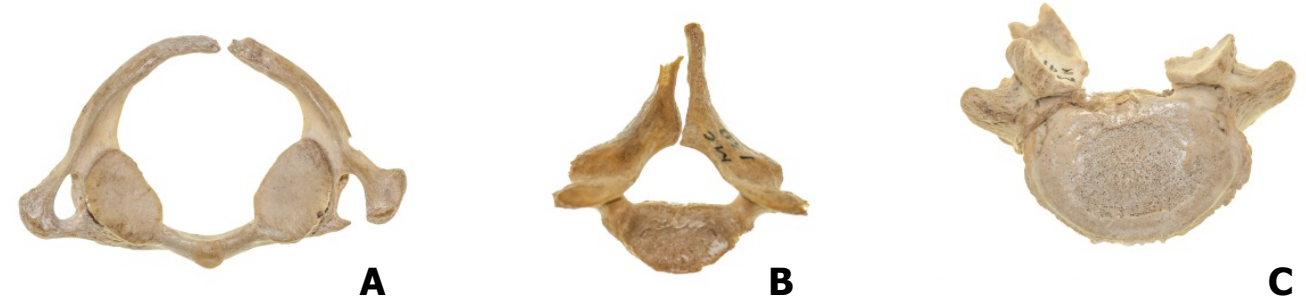

C

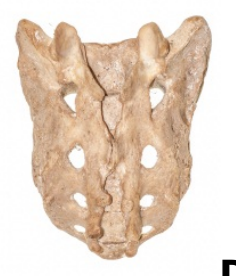

Figure 1 shows examples of vertebrae with neural arch defects from the different spinal segments; cervical (A),

thoracic (B), lumbar (C) and the sacrum (D)

In table 2, the overall crude prevalence rate of spina bifida was the equivalent of 190 defects per 1,000 births. Also note that, the incidence of spina bifida was higher in bones from the general population (Banyankole and Bakiga) than in the skeletons of individuals from Rwanda and Burundi who at the time were in the country as refugees.

Table 2 Distribution of spina bifida by tribe in the Galloway skeletal collection

\begin{tabular}{lllll}
\hline TRIBE & $\begin{array}{l}\text { Spina- } \\
\text { bifida }\end{array}$ & Normal & Total & $\begin{array}{l}\text { Crude prevalence }(/ 1000 \\
\text { births })\end{array}$ \\
\hline RWANDESE & $16(22.5 \%)$ & $55(77.5 \%)$ & 71 & 225 \\
BARUNDI & $4(17 \%)$ & $19(83.0 \%)$ & 23 & 173 \\
BAKIGA & $5(45.5 \%)$ & $6(54.5 \%)$ & 11 & 454 \\
BANYANKOLE & $4(29 \%)$ & $10(71.00 \%)$ & 14 & 285 \\
OTHERS & $14(13 \%)$ & $93(87.0 \%)$ & 107 & 150 \\
Total & $43(19 \%)$ & $183(81.0 \%)$ & 226 & 190
\end{tabular}

Overall, there were 60 vertebrae with neural arch defects. Most involved was the sacrum (38) followed by the lumbar (11), cervical (7) and thoracic spine (4). The first sacral vertebra (S1) was the most involved vertebra; and all cervical defects involved the ring of the first cervical vertebra (C1). There were 11 skeletons with multiple level spina bifida. 


\section{DISCUSSION}

This study set out to determine the occurrence of spina bifida in the skeletons in the Galloway skeletal collection at Makererere University College of Health Sciences, Anatomy department. We found 43 (19\%) of the 226 examined skeletons had some form of spina bifida defect. As demonstrated in figure 1 above, these minor defects ranged from a small notch in the vertebral arch to complete absence of a bone. The defects in these individuals passed unnoticed during life only to be identified on examination of the bones after death. As summarised in table 2 this corresponds to a rate of 190 defects per 1000 births for the population represented in the collection. This is very high when compared with prevalence rates based on observational studies in the region (Githuku et al., 2014).

Some of the possible explanations for the very high rates of the spina bifida deformities observed in the skeletons from the Galloway osteological collection include: (1) the nature of the skeleton donors; most of the skeletons in the collection were from unclaimed bodies. These unclaimed bodies were usually from individuals of low social economic status, refugees or migrant workers. Such individuals tend to be socially isolated with very few relatives to perform the ritual burial ceremonies that characterise most African societies. It is important to note that even today individuals conceived in such communities face a myriad of challenges like; poor health, limited access to care, no education etc., as a result of their disadvantaged status in society. From table 1 observe that most of the bones in the collection were of Rwandese origin. This group and the people from Burundi were being hosted in refugee camps in various parts of Uganda dating back from the 1930s. When compared with the native Banyankole and Bakiga, we note in table 2, that the rates of spina bifida were higher in the natives. This brings us to the second reason for the high rates of spina bifida in this study population. (2) The low levels of dietary folic acid in the local foods available to the general population. Neural tube defects develop in the first 2 months of gestation and these defects manifest after birth. This development can be affected by Micro nutrient malnutrition, maternal spacing of pregnancies (inter pregnancy period) and parity (Bell \& Oakley, 2009). It is possible that the individuals in the refugee camps were receiving fortified foods thus increasing their access to folic acid. This was not the case for the natives in particular the Bakiga who are typically subsistence farmers.

The last possible explanation for the high numbers of individuals with spina bifida in this collection (3) is the fact that individuals with this form of defect are more prone to death compared to the normal population (Kancherla et al., 2014). This when combined with the previously mentioned observation could have resulted in a concentration of skeletons with defects in the collection.

It was not possible to make a more detailed comparison because of the following limitations: the absence of systematic studies in the study population at the time; the absence of further additions to the Galloway collection due to the war and insecurity in Uganda during the 1970 s to the early 1980 s on which to observe trends. The potential for observing trends in the rates of spina bifida is supported by literature showing differences in the incidence of spina bifida (Dodge \& McKinney, 1964; Simpkiss \& Lowe, 1961).

Study had limitations: the ethnic group of many of the skeletons could not be ascertained and this may potentially have affected our percentages and inferences.

\section{Conclusions}

This historical study highlights possible differences in the maternal micro nutrient status in the early months of pregnancy for various African populations as shown by the differences in the prevalence rates of minor spina bifida defects in the Galloway osteological collection. There is need for baseline studies on folic acid levels during pregnancy and the various local dietary sources of folic acid for Africans. 


\section{Conflict of interest}

The author(s) declare(s) that there is no conflict of interests regarding the publication of this paper.

\section{Authors' contributions}

All authors contributed in the assessment of vertebrae and manuscript writing. All authors read and approved the final manuscript

\section{REFERENCES}

1. Bell KN, Oakley GP. 2009. Update on prevention of folic acid-preventable spina bifida and anencephaly. Birth Defects Research Part A: Clinical and Molecular Teratology, 85(1), 102107.

2. Botto LD, Moore, CA, Khoury, MJ, \& Erickson, JD. 1999. Neural-tube defects. N Engl J Med, 341(20), 1509-1519.

3. Dodge O, \& McKinney, B 1964. Causes of perinatal death in Uganda Africans, with special reference to congenital malformations. J Pediatr, 65(2), 267-269.

4. Flores, A, Vellozzi C, Valencia D, \& Sniezek, J. 2014. Global Burden of Neural Tube Defects, Risk Factors, and Prevention. Indian Journal of Community Health, 26.

5. Githuku JN, Azofeifa A, Valencia D et al. 2014. Assessing the prevalence of spina bifida and encephalocele in a Kenyan hospital from 2005-2010: implications for a neural tube defects surveillance system. Pan Afr Med J, 18, 60.

6. Greene ND, \& Copp A J. 2014. Neural tube defects. Annu Rev Neurosci, 37, 221-242.

7. Kancherla V, Druschel CM, \& Oakley GP Jr. 2014. Population-based study to determine mortality in spina bifida: New York State Congenital Malformations Registry, 1983 to 2006. Birth Defects Res A Clin Mol Teratol, 100(8), 563-575.

8. Kish, L. 1965. Survey sampling.

9. Naing NN. 2000. Easy way to learn standardization: Direct and Indirect Methods. The Malaysian journal of medical sciences: MJMS, 7(1), 10.

10. Ochieng J, Kiryowa H, Munabi I, \& Ibingira CBR. 2011. Prevalence, nature and characteristics of external congenital anomalies at Mulago Hospital. East and Central African Journal of Surgery, 16(1).

11. Padmanabhan R. 2006. Etiology, pathogenesis and prevention of neural tube defects. Congenit Anom (Kyoto), 46(2), 55-67.

12. Simpkiss M, \& Lowe A. 1961. Congenital abnormalities in the African newborn. Archives of disease in childhood, 36(188), 404.

13. Warf BC, Wright III E J, \& Kulkarni AV. 2011. Factors affecting survival of infants with myelomeningocele in southeastern Uganda: Clinical article. Journal of Neurosurgery: Pediatrics, 7(2), 127-133.

14. Wood B. 2013. Phillip Vallentine Tobias (1925-2012). Journal of anatomy, 222(6), 571-572. 